\title{
Caracterização de frutos de mangabas (Hancornia speciosa Gomes) e estudo de processos de extração da polpa
}

\section{Danielle Godinho Araújo Perfeito ${ }^{1}$, Natália Carvalho², Milene Cristina Mendes Lopes ${ }^{1}$, Flávio Luís Schmidt ${ }^{2}$}

${ }^{1}$ Instituto Federal Goiano - IF Goiano, Campus Urutaí, Urutaí, Goiás, Brasil. E-mail: daniellegodinhoaraujo@ hotmail.com, milenecristinast@hotmail.com

${ }^{2}$ Universidade Estadual de Campinas - UNICAMP, Faculdade de Engenharia de Alimentos - FEA. Campinas, São Paulo, Brasil. E-mail: nataliatrica@fea.unicamp.br,schmidt@fea.unicamp.br

Recebido: 02/06/2015; Aceito: 13/08/2015.

\section{RESUMO}

Estudos visando aprimorar a tecnologia de pós-colheita da mangaba se fazem necessários em função da alta perecibilidade da fruta e falta de tecnologias de transformação adaptáveis às condições de microempresas. Nesse estudo frutos de mangaba com três estágios de maturação foram caracterizados quanto a suas propriedades físicas e químicas, além disso foram avaliadas diferentes formas de despolpamento dos frutos em função do rendimento e características da polpa. As características físicas dos frutos determinadas foram o comprimento, diâmetro, massa específica aparente, volume e massa específica. Determinou-se o uso de prévia redução de tamanho dos frutos em multiprocessador sob aquecimento e dois tipos de peneiras em extrator, tipo escovas: com 0,8 e 0,5 mm de diâmetro de abertura de malha. A massa foi o parâmetro físico estudado que apresentou a maior irregularidade, variando entre 9,96 e 67,8 g por fruto. Houve aumento do conteúdo de vitamina $\mathrm{C}$ no transcorrer do processo de maturação dos frutos de mangaba do Cerrado atingindo $59,16 \mathrm{mg} 100 \mathrm{~g}^{-1}$ em frutos maduros. Nas operações de despolpamento avaliadas verificou-se que o branqueamento e a trituração prévia dos frutos não aumentaram o rendimento de polpa, que foi expressivo, em torno de $77 \%$, indicando que a mangaba é um fruto promissor para a agroindústria.

Palavras-chave: Cerrado, polpa de fruta, despolpamento, frutos tropicais.

\section{Mangaba (Hancornia speciosa Gomes) fruit characterization and study the pulp extraction processes}

\section{ABSTRACT}

Studies to improve mangaba post-harvest technology are necessary due to the highly perishable fruit and lack of adaptive processing technologies to the conditions of small businesses. In this study, mangaba fruits with three maturity stages were characterized for their physical and chemical properties; and were also evaluated different pulping technologies of fruits on pulp yield and characteristics. The length, diameter, apparent specific mass, volume and density of mangaba fruits were measured. The use of previous reduction in fruit size with multiprocessor under heating and two kinds of sieves extractor brushes type: 0.8 and $0.5 \mathrm{~mm}$ mesh opening diameter were tested. The fruit mass was physical property with the highest range of variation (from 9.96 to $67.8 \mathrm{~g}$ per fruit). There was increase in the vitamin $\mathrm{C}$ content during the maturation process of mangaba fruits reaching

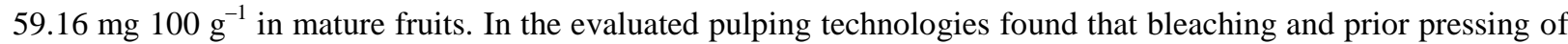
the fruits did not increase the pulp yield, which was significant $(77 \%)$, indicating that the mangaba is a promising fruit for agribusiness.

Key words: Cerrado, fruit pulp, pulping, tropical fruits. 


\section{Introdução}

O fruto da mangabeira é do tipo baga com formato elipsóide e/ou arredondado (PEREIRA et al., 2006). Apresenta polpa amarela esverdeada, aromática, adocicada, com sabor característico e muito apreciada pela população do Cerrado brasileiro. Na região CentroOeste do Brasil a polpa de mangaba é muito aproveitada para fabricação de sorvetes.

Considerando a sazonalidade e a perecibilidade do fruto, o conhecimento das características físicas, como volume e massa específica são de extrema importância para o dimensionamento de silos de armazenamento e máquinas dentro da linha de processamento agroindustrial, assim como para a definição das formas mais adequadas para o processamento, incluindo etapas básicas como limpeza e seleção.

O método de extração de polpa aplicado a uma fruta é muito importante ao processamento já que pode afetar o rendimento e as características sensoriais do produto final. $\mathrm{O}$ aumento do rendimento em detrimento da qualidade é uma escolha a ser estudada (DIB TAXI et al., 2003).

O ponto ideal de colheita da mangaba é de difícil determinação e representa um dos fatores que limitam a exploração da cultura. $\mathrm{O}$ fruto quando maduro tem melhor sabor e menor teor de látex. No entanto, não há sinais de mudanças muito marcantes e visíveis nos frutos, como ocorre na maioria das espécies frutíferas. Em mangabas da Caatinga, onde predomina a variedade botânica speciosa, os sinais são mais evidentes em relação àquelas do Cerrado, pois quando maduras ou semimaduras (fruto de vez) apresentam manchas avermelhadas, consistência levemente macia ou macia e coloração mais amarelada. Em geral, mangabas do Cerrado apresentam bem maiores do que as do nordeste e não apresentam manchas avermelhadas quando maduras, caracteríscas de frutos das variedades pubescens e gardneri (PEREIRA et al., 2006).

Os objetivos desse estudo foram caracterizar quimicamente os frutos mangabas com três estágios de maturação, quantificar as características físicas dos frutos já amadurecidos e avaliar diferentes formas de despolpamento dos frutos em função do rendimento e características da polpa.

\section{Material e Métodos}

Os frutos mangaba foram adquiridos na Estação Experimental da Universidade Estadual de Goiás, Unidade Universitária de Ipameri. Para caracterização física, os frutos, ainda verdes e semimaduros, correspondentes à safra de 2010, foram colhidos diretamente das plantas e transportados em caixas de papelão para o Laboratório de Frutas e Hortaliças do Departamento de Tecnologia de Alimentos da
Universidade Estadual de Campinas. Os frutos permaneceram acondicionados nas caixas de papelão até a completa maturação, para então iniciar a caracterização física dos frutos maduros. Os frutos verdes e semimaduros foram retirados das caixas e analisados em seguida. Os frutos utilizados nos despolpamentos correspondem à mesma safra, no entanto, foram transportados congelados.

A avaliação dos frutos de mangaba em diferentes estágios de maturação foi realizada considerando três estágios de maturação, denominados: verde (fruto com a casca totalmente verde e textura firme); semimaduro ou "de vez" (fruto ligeiramente amarelado e textura tenra); e maduro (fruto verde-amarelado e com textura macia).

\section{Avaliação física dos frutos}

Foram selecionados aleatoriamente 100 frutos maduros para avaliação de características físicas como comprimento e diâmetro. Essa avaliação foi realizada com auxílio de um paquímetro Mitutoyo ${ }^{\circledR}$, precisão \pm 0,05 mm. Para determinação do rendimento médio, os frutos foram descascados manualmente separando a casca, semente e polpa seguida de determinação da massa relativa a cada componente. $\mathrm{O}$ rendimento dos frutos foi calculado considerando a massa da polpa mais casca em porcentagem da massa total. Também foi observado visualmente o formato dos frutos.

A massa específica aparente $\left(\rho_{\mathrm{Ap}}\right)$ foi encontrada através do quociente da massa de frutos com o volume ocupado por esses frutos medido em uma proveta de $1000 \mathrm{~mL}$, realizado em triplicata.

O volume foi determinado por imersão do fruto em água destilada à temperatura ambiente, contida em uma proveta de $1000 \mathrm{~mL}$ e observado o volume de água deslocado pela diferença modular da altura do líquido antes e após a imersão. A massa específica foi determinada pelo quociente da massa do fruto em balança semi-analítica, Gehaka ${ }^{\circledR} \mathrm{BG}-4000$ com precisão $\pm 0,01 \mathrm{~g}$ e o volume previamente determinado.

\section{Caracterização dos frutos em diferentes estágios de maturação}

A polpa dos frutos previamente classificados, segundo os três estágios de maturação já citados anteriormente, foram caracterizados por meio das seguintes análises químicas: acidez total titulável, avaliada segundo método $\mathrm{n}^{\circ} 942.15$ da AOAC (1997) e expressa em porcentagem de ácido cítrico; $\mathrm{pH}$ medido em potenciômetro Digimed ${ }^{\circledR}$ DM-20, calibrado com soluções-tampão em pH 4 e 7 à $20^{\circ} \mathrm{C}$, segundo método $\mathrm{n}^{\circ} 981.12$ da AOAC (1997); sólidos solúveis, determinados baseados na leitura direta dos graus Brix da amostra a $20{ }^{\circ} \mathrm{C}$ em refratômetro digital da marca LEICA, mod. AR200; sólidos totais, obtidos por secagem em estufa Tecnal TE394/1, com circulação e 
renovação de ar, a $85{ }^{\circ} \mathrm{C}$, segundo método $\mathrm{n}^{\circ} 920.151$ da AOAC (1997); teor de ácido ascórbico, detectado pelo método $\mathrm{n}^{\circ} 43.065$ da AOAC (1984), modificado por Benassi e Antunes (1988) que se baseia na redução de 2,6-diclorofenolindofenol-sódico (DCFI) pelo ácido ascórbico.

A determinação instrumental da cor foi executada em espectrofotômetro Colorquest Hunterlab (1996), usando sistema de leitura CIELAB, em que $\mathrm{L}^{*}$ corresponde luminosidade com valor máximo de 100 (branco) e mínimo de 0 (preto); os eixos $a^{*}$ e $b^{*}$ não apresentam limites numéricos específicos. A coordenada $\mathrm{a}^{*}$ varia do vermelho $\left(+\mathrm{a}^{*}\right)$ ao verde $(-\mathrm{a} *)$, e a coordenada $b^{*}$ do amarelo $\left(+b^{*}\right)$ ao azul $\left(-b^{*}\right)$ (GANGA et al., 2010). A leitura foi realizada tomando como base 10 pontos diferentes em cada fruto. O "ratio" foi calculado pelo quociente de sólidos solúveis totais (\%) e acidez total titulável (\%).

A textura foi determinada em texturômetro Stable Micro Systems ${ }^{\circledR}$ TA-XT2i utilizando a ponta de prova (probe) tipo agulha $\mathrm{P} 2 \mathrm{~N}$, com velocidades de perfuração de $5 \mathrm{~mm} \mathrm{~s}^{-1}$ para o pré-teste; $0,5 \mathrm{~mm} \mathrm{~s}^{-1}$ para o teste e 5 $\mathrm{mm} \mathrm{s}^{-1}$ para o pós-teste. A distância de perfuração foi padronizada em $3 \mathrm{~mm}$, que correspondeu a ruptura da casca dos frutos e o resultado expresso pela força $(\mathrm{N})$. Três frutos de cada estágio de maturação e quatro pontos diferentes da região equatorial dos frutos foram submetidos ao teste.

\section{Despolpamento}

Os lotes de $9 \mathrm{~kg}$ de frutos maduros foram descongelados e sanitizados em solução de hipoclorito de sódio $\left(50 \mathrm{mg} \mathrm{L}^{-1}\right)$ por 15 minutos com posterior enxágue com água potável. As polpas foram obtidas em extrator de escovas da marca Sterling. Foi avaliado o uso de prévia redução de tamanho dos frutos em multiprocessador Stephan, marca Geiger $^{\circledR}$, sob aquecimento e dois tipos de peneiras no extrator com $0,8 \mathrm{~mm}$ e $0,5 \mathrm{~mm}$ de diâmetro de abertura de malha (Figura 1). As operações correspondentes a cada despolp amento teste foram realizadas em duplicata.

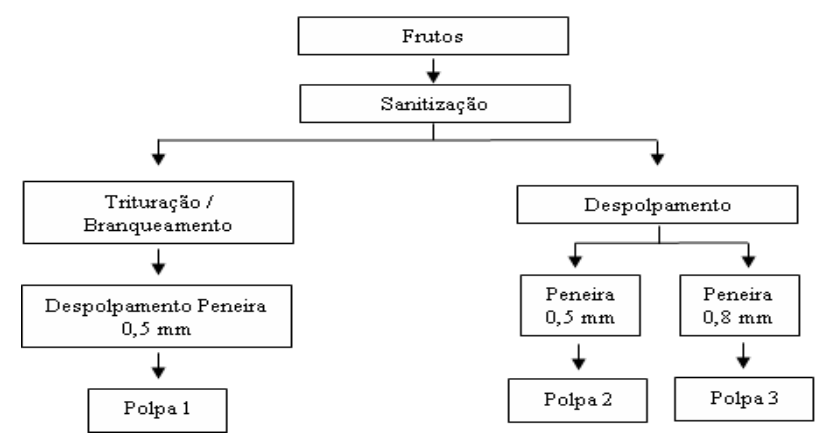

Figura 1. Fluxograma das extrações das polpas dos frutos de mangaba. Fonte: Elaboração dos autores.
A etapa de trituração/branqueamento foi realizada em equipamento Stephan empregando temperatura de $70{ }^{\circ} \mathrm{C}$ por $3 \mathrm{~min}$. Os frutos triturados e branqueados foram submetidos à extração da polpa utilizando peneira de $0,5 \mathrm{~mm}$ de diâmetro de abertura de malha no extrator (Polpa 1) e os frutos não submetidos ao branqueamento foram despolpados utilizando a peneira de $0,5 \mathrm{~mm}$ (Polpa 2) e 0,8 mm de diâmetro de abertura de malha (Polpa 3).

As polpas foram embaladas à vácuo em sacos de polietileno contendo cerca de $500 \mathrm{~g}$ de polpa utilizando seladora SELOVAC ${ }^{\circledR} 200 S$, para posterior congelamento. O rendimento das diferentes operações de despolpamento foi calculado em porcentagem tomando como base a massa inicial dos frutos e a massa de polpa obtida. A massa não correspondente à polpa ou resíduo, não expressa em valor numérico, é quantificada como perdas inerentes aos processamentos. Os resultados foram expressos com os valores médios \pm desvio padrão.

\section{Avaliações físico-químicas das polpas}

Foram determinados $\mathrm{pH}$, acidez total titulável, sólidos solúveis, sólidos totais, teor de ácido ascórbico e cor, conforme metodologias previamente citadas para avaliação dos frutos. As análises foram realizadas em triplicata nas polpas de mangaba e os resultados foram submetidos ao teste de média de Tukey no programa estatístico SAS. Os resultados foram expressos com os valores médios \pm desvio padrão.

\section{Resultados e Discussão}

\section{Características físicas dos frutos}

Os frutos apresentaram grande variação nos parâmetros avaliados. A massa foi o parâmetro estudado que apresentou maior variação (Tabela 1). No estudo de Souza et al. (2007) a massa dos frutos também mostrou grande variação, oscilando entre 21,74 e 42,07 g. Os valores encontrados para o comprimento e diâmetro médio dos frutos foram similares aos determinados por Souza et al. (2007). A massa específica da Hancornia speciosa teve como valor médio $0,84 \mathrm{~g} \mathrm{~cm}^{-3}$, ou seja, densidade inferior à da água. Tal característica pode ser um dado importante em técnicas de separação dos frutos em sistemas de seleção por processos hidrodinâmicos.

O rendimento dos frutos foi de $72,51 \%$ (Tabela 2), o que corresponde ao percentual de polpa e casca do fruto já que no processo de despolpamento em extrator a casca é incorporada à polpa. Ganga et al. (2010) observaram que os frutos de $H$. speciosa da variedade cuyabensis apresentaram rendimento de $68,88 \%$, menor rendimento de polpa mais casca dentre as variedades estudadas. A média de rendimento nas diferentes variedades naturais de $H$. speciosa do Cerrado foi de $82,68 \%$ e a massa de sementes foi de $3,88 \mathrm{~g}$. 
Tabela 1. Caracterização física dos frutos mangaba

\begin{tabular}{lccc}
\hline \multicolumn{1}{c}{ Parâmetro } & Máximo & Mínimo & Média \pm Desvio Padrão \\
\hline Comprimento $(\mathrm{mm})$ & 55,20 & 26,00 & $38,78 \pm 5,34$ \\
Diâmetro $(\mathrm{mm})$ & 50,60 & 24,20 & $35,43 \pm 5,20$ \\
Massa $(\mathrm{g})$ & 67,80 & 9,96 & $28,71 \pm 11,17$ \\
Densidade aparente $\left(\mathrm{g} \mathrm{cm}^{-3}\right)$ & 0,42 & 0,39 & $0,40 \pm 0,02$ \\
Volume $\left(\mathrm{cm}^{3}\right)$ & 73,00 & 20,00 & $42,40 \pm 12,74$ \\
Densidade específica $\left(\mathrm{g} \mathrm{cm}^{-3}\right)$ & 0,95 & 0,79 & $0,84 \pm 0,01$ \\
\hline
\end{tabular}

A avaliação do formato dos frutos revelou que $77 \%$ dos mesmos correspondem ao formato oblongo, ou seja, apresentam comprimento maior que o diâmetro, e $23 \%$ com formato arredondado, comprimento menor ou igual ao diâmetro. Dentre o grupo de frutos oblongos o menor diâmetro foi $24,2 \mathrm{~mm}$ e o maior $43,8 \mathrm{~mm}$, já no grupo dos frutos redondos o menor diâmetro foi $26,4 \mathrm{~mm}$ e o maior 50,6 mm. De acordo com Ganga et al. (2010) as variedades de mangaba gardneri e pubescens predominam frutos redondos e verde-claros, enquanto nas variedades speciosa e cuyabensis predominam frutos de formato oblongo e coloração amarelo-escura e verde-escura, respectivamente. Uma maior amostragem de mangabas com formato oblongo e mangabas com formato redondo, sendo os frutos cultivados em condições controladas e homogêneas seria necessário para propor uma classificação, assim como existe para o tomate e outros frutos.

Tabela 2. Valores médios e desvio padrão das diferentes partes do fruto mangaba.

\begin{tabular}{lc}
\hline \multicolumn{1}{c}{ Parâmetro } & Média \\
\hline Massa (g) & $28,71 \pm 11,17$ \\
Massa casca $(\mathrm{g})$ & $3,57 \pm 1,29$ \\
Massa polpa $(\mathrm{g})$ & $17,11 \pm 7,10$ \\
Massa semente $(\mathrm{g})$ & $6,07 \pm 3,31$ \\
Rendimento $(\%)$ & $72,51 \pm 7,98$ \\
\hline
\end{tabular}

Características físico-químicas dos frutos em diferentes estágios de maturação

O resultado da caracterização das mangabas nos três diferentes estágios de maturação revela um aumento no $\mathrm{pH}$ durante o processo de amadurecimento, acompanhado de uma redução da acidez (Tabela 3). Porém, a acidez não difere no fruto semi maduro em relação ao fruto maduro ( $p>0,05)$. Durante a maturação é comum o decréscimo de ácidos orgânicos uma vez que estes são utilizados como substratos no processo respiratório (CHITARRA; CHITARRA, 2005). Carnelossi et al. (2004) avaliaram as características físico-químicas de mangabas maduras e "de vez" na região de Itaporanga D’Ajuda/SE e não observou variação no valor do $\mathrm{pH} 3,5$ com a maturação. A acidez encontrada por Carnelossi et al. (2004) foi de 0,7 e $0,8 \%$ nas mangabas maduras e "de vez" respectivamente, assim como nesse trabalho, não houve diferença significativa na acidez $(p>0,05)$ dos frutos desses dois estágios de maturação.

Silva et al. (2009) avaliaram mangabas também em três estágios de maturação, verde, início de maturação e maduro, e encontraram valores inferiores 0,$35 ; 0,34$; $0,31 \%$ respectivamente, ao encontrado nesse trabalho para acidez 0,$95 ; 0,84 ; 0,84 \%$. O pH dos frutos avaliados por Silva et al. (2009) foi de 3,10;3,37; 3,40 também valores menores aos encontrados nesse estudo.

O aumento do teor de sólidos solúveis é bem caracterizado conforme procede a maturação do fruto. As substâncias dissolvidas, principalmente açúcares, tendem a aumentar com a maturação, o que caracteriza a doçura do fruto. Silva et al. (2009) encontraram os menores valores de sólidos solúveis para mangabas verdes de 8,47, valor próximo ao determinado nesse trabalho para os frutos do estágio de maturação verde. As variações dos parâmetros físicos e químicos podem ser influenciadas pelas características fisiológicas, genéticas, estágio de maturação, estrutura biológica do fruto e a composição do solo.

Os frutos verdes apresentaram maior umidade com relação aos frutos avaliados nos outros estágios de maturação. No início da maturação há um aumento da permeabilidade das membranas permitindo o acesso de substratos às enzimas e consequente intensificação do metabolismo o que acarreta em perda de água.

O teor de ácido ascórbico dos frutos da região Sudeste de Goiás foi inferior aos encontrados por Carnelossi et al. (2004) para frutos do nordeste que apresentaram entre 250 e $300 \mathrm{mg} 100 \mathrm{~g}^{-1}$, o que pode ser explicado pelas diferentes variedades botânicas dos frutos da mangabeira predominantes no Cerrado Goiano. Assim como Silva et al. (2009) observou um aumento do conteúdo de vitamina $\mathrm{C}$ no transcorrer do processo de maturação para mangabas do Cerrado (26,1 $\mathrm{mg} 100 \mathrm{~g}^{-1}$ para frutos maduros), neste estudo também o teor de ácido ascórbico foi maior nos frutos maduros $\left(59,16 \mathrm{mg} 100 \mathrm{~g}^{-1}\right)$. O aumento do teor da vitamina C pode ser explicado pela atuação do ácido ascórbico como antioxidante em resposta às aceleradas reações oxidativas que ocorrem durante o amadurecimento através do aumento da síntese de metabólitos 
intermediários que promovem a síntese da glicose-6fostato, a precursora imediata do ácido ascórbico. A mangaba ainda apresentou conteúdo de vitamina $\mathrm{C}$ superior a outros frutos do Cerrado como cagaita 27,46

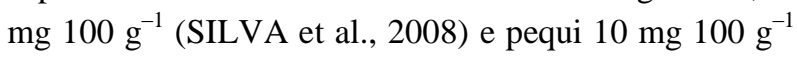
(SILVA et al., 2009).

Tabela 3. Valores médios e desvio padrão dos parâmetros físicos e químicos dos frutos nos diferentes estágios de maturação.

\begin{tabular}{lccc}
\hline \multicolumn{1}{c}{ Parâmetro } & Fruto Verde & Fruto Semi Maduro & Fruto Maduro \\
\hline pH & $3,47 \pm 0,05 \mathrm{c}$ & $3,79 \pm 0,05 \mathrm{~b}$ & $3,97 \pm 0,03 \mathrm{a}$ \\
Acidez (\% ác. cítrico) & $0,95 \pm 0,01 \mathrm{a}$ & $0,84 \pm 0,02 \mathrm{~b}$ & $0,84 \pm 0,02 \mathrm{~b}$ \\
Sólidos Solúveis ( ${ }^{\circ}$ Brix) & $8,83 \pm 0,35 \mathrm{c}$ & $13,77 \pm 0,40 \mathrm{~b}$ & $17,53 \pm 0,38 \mathrm{a}$ \\
"Ratio" & $9,29 \pm 0,29 \mathrm{c}$ & $16,39 \pm 0,52 \mathrm{~b}$ & $20,87 \pm 0,49 \mathrm{a}$ \\
Umidade (\%) & $87,94 \pm 0,86 \mathrm{a}$ & $82,08 \pm 0,01 \mathrm{~b}$ & $83,55 \pm 0,25 \mathrm{~b}$ \\
Ácido ascórbico (mg/100g) & $5,72 \pm 0,76 \mathrm{c}$ & $34,57 \pm 0,78 \mathrm{~b}$ & $59,16 \pm 2,04 \mathrm{a}$ \\
Textura (N) & $18,47 \pm 0,97 \mathrm{a}$ & $17,73 \pm 1,60 \mathrm{a}$ & $0,58 \pm 0,07 \mathrm{~b}$ \\
Cor & & & \\
L* & $61,36 \pm 0,95 \mathrm{~b}$ & $64,89 \pm 1,63 \mathrm{a}$ & $61,87 \pm 1,13 \mathrm{~b}$ \\
$\mathrm{a} *$ & $-10,14 \pm 1,13 \mathrm{~b}$ & $-4,61 \pm 4,68 \mathrm{ab}$ & $0,11 \pm 7,58 \mathrm{a}$ \\
$\mathrm{b}^{*}$ & $46,03 \pm 0,88 \mathrm{~b}$ & $51,06 \pm 2,82 \mathrm{a}$ & $52,94 \pm 2,40 \mathrm{a}$ \\
\hline
\end{tabular}

Médias com expoentes diferentes em uma mesma linha indicam diferença estatística $(\mathrm{p} \leq 0,05)$

A textura no fruto maduro é expressivamente diferente quando comparado ao fruto "de vez" e verde (Tabela 3). Ocorre uma redução significativa na força aplicada para penetração da haste do texturômetro no fruto quando maduro o que confirma que o parâmetro textura é um bom indicativo de maturação das mangabas do cerrado.

$\mathrm{Na}$ cor, observa-se variações na coordenada $a^{*}$ que varia do vermelho $\left(+\mathrm{a}^{*}\right)$ ao verde $\left(-\mathrm{a}^{*}\right)$, porém, mesmo nos frutos maduros a coloração verde aparece e a tonalidade vermelha quase não é observada. A coordenada $a^{*}$ do fruto verde não apresentou diferença estatística $(p>0,05)$ com relação à dos frutos semimaduro e maduro. A coordenada $b^{*}$ aumentou ligeiramente no fruto maduro; e isso indica um aumento da tonalidade amarela, no entanto, não diferiu estatisticamente $(p>0,05)$ do fruto semimaduro. Essas observações comprovam a dificuldade de determinação do ponto de colheita nas mangabas do Cerrado.

\section{Despolpamento e avaliação das polpas}

$\mathrm{O}$ rendimento das operações de despolpamento (Tabela 4) evidencia que a mangaba apresenta alto rendimento em polpa, principalmente quando comparado a outros frutos tropicais como pitanga, cajá e umbu. Mattietto et al. (2007) avaliaram a extração de polpas de umbu e cajá em despolpador tipo escovas utilizando peneira de $0,8 \mathrm{~mm}$ de diâmetro de abertura e obteve rendimento em polpa de 42,35 e $33,25 \%$ respectivamente.

$\mathrm{O}$ branqueamento e trituração do fruto anterior à extração da polpa não interferiu no rendimento da operação. Os frutos da mangabeira, quando maduros, apresentam textura extremamente macia o que pode ter facilitado a operação de despolpamento e poderia justificar o fato do aquecimento e trituração das mangabas não influenciar no rendimento de extração da polpa.

A polpa resultante da operação com trituração e branqueamento apresentou pontos escuros (marrons) que correspondem à película que recobre as sementes dos frutos. Além do comprometimento da aparência, essa operação também alterou sensorialmente o produto desenvolvendo um sabor amargo que foi detectado pela avaliação sensorial realizada pela equipe técnica do Laboratório de Frutas e Hortaliças.

O despolpamento utilizando a peneira de $0,8 \mathrm{~mm}$ de diâmetro de abertura proporcionou um aumento no rendimento do processo, porém, a polpa obtida foi de qualidade inferior à polpa na extração com a peneira de $0,5 \mathrm{~mm}$ de diâmetro que ficou mais refinada e com uma aparência mais agradável observada pela equipe técnica do Laboratório.

As avaliações químicas das polpas oriundas das diferentes extrações não revelam grandes diferenças nas características químicas das polpas para a maioria dos atributos avaliados (Tabela 5).

Os teores de sólidos solúveis das polpas obtidas pelas diferentes formas de extração apresentaram diferenças estatisticamente significativas $(p \leq 0,05)$, a amostra sem branqueamento e refinada em peneira de $0,5 \mathrm{~mm}$ tem maior teor de sólidos solúveis provavelmente devido ao menor conteúdo de casca incorporado (menor conteúdo de fibras), já na polpa oriunda da peneira de $0,8 \mathrm{~mm}$ o conteúdo de casca incorporada ao produto final é maior o que justifica o menor conteúdo de sólidos solúveis.

As três polpas obedeceram aos padrões de identidade e qualidade, fixados pelo Ministério da Agricultura Pecuária e Abastecimento (MAPA) para a polpa de mangaba nas características avaliadas. $\mathrm{O}$ MAPA estabelece sólidos solúveis mínimo de $8, \mathrm{pH}$ 
mínimo de 2,8, acidez total mínimo de $0,7{\mathrm{~g} 100 \mathrm{~g}^{-1} \mathrm{e}}$

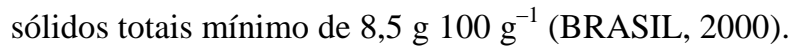

O conteúdo de ácido ascórbico foi superior no despolpamento com trituração/branqueamento prévio do fruto e, a princípio, poderia ser explicada pelo $\mathrm{pH}$ ligeiramente menor dos frutos processados no ensaio realizado com branqueamento. Em geral, com o amadurecimento, os frutos diminuem a acidez e o teor de ácido ascórbico (CARNELOSSI et al., 2004).

No entanto, para a mangaba, Silva et al. (2009) observou um ligeiro aumento do teor de vitamina $\mathrm{C}$ com o amadurecimento dos frutos. Estes fatos comprovam que muitos frutos do cerrado podem apresentar heterogeneidade de forma, cor e atributos físicoquímicos, também apontados por outros autores (DIB TAXI et al., 2003, BORGES et al., 2010).

Os valores encontrados para os parâmetros de cor (L, a, b) das polpas extraídas nas diferentes condições de processamento são mostrados na Tabela 6. Os dados obtidos revelam diferenças estatísticas $(p \leq 0,05)$ nos parâmetros de cor indicando que as condições de extração da polpa podem influenciar significativamente na aparência do produto final provavelmente devido a variações no conteúdo de casca incorporados à polpa, principalmente quando utilizada a peneira de $0,8 \mathrm{~mm}$ de diâmetro de abertura de malha.

Tabela 4. Rendimento das operações de despolpamento

\begin{tabular}{lll}
\hline Despolpamento & Polpa (\%) & Resíduo (\%) \\
\hline Com branqueamento (peneira de 0,5mm) & $77,68 \pm 1,29$ & $17,19 \pm 1,68$ \\
Sem branqueamento (peneira de 0,5mm) & $77,43 \pm 1,61$ & $15,67 \pm 0,87$ \\
Sem branqueamento (peneira de 0,8mm) & $84,30 \pm 1,05$ & $11,97 \pm 0,72$ \\
\hline
\end{tabular}

Tabela 5. Caracterização das polpas dos diferentes despolpamentos

\begin{tabular}{|c|c|c|c|c|c|}
\hline Despolpamento & $\begin{array}{c}\text { Sólidos Solúveis } \\
\left({ }^{\circ} \text { Brix }\right)\end{array}$ & pH & $\begin{array}{l}\text { Acidez total titulável } \\
\qquad\left(\mathrm{g} 100 \mathrm{~g}^{-1}\right)\end{array}$ & $\begin{array}{c}\text { Sólidos Totais } \\
(\%)\end{array}$ & $\begin{array}{l}\text { Ácido ascórbico } \\
\qquad\left(\mathrm{mg} \mathbf{1 0 0}^{-1} \mathrm{~g}\right)\end{array}$ \\
\hline $\begin{array}{l}\text { Com branqueamento } \\
\text { (peneira de } 0,5 \mathrm{~mm} \text { ) }\end{array}$ & $15,60 \pm 0,0 b$ & $3,51 \pm 0,1 \mathrm{a}$ & $1,08 \pm 0,0 \mathrm{a}$ & $18,00 \pm 0,1 b$ & $25,39 \pm 1,0 \mathrm{a}$ \\
\hline $\begin{array}{l}\text { Sem branqueamento } \\
\text { (peneira de } 0,5 \mathrm{~mm} \text { ) }\end{array}$ & $15,70 \pm 0,0 \mathrm{a}$ & $3,57 \pm 0,1 \mathrm{a}$ & $1,06 \pm 0,0 \mathrm{a}$ & $18,58 \mathrm{~b} \pm 0,1 \mathrm{a}$ & $19,95 \pm 1,0 b$ \\
\hline $\begin{array}{l}\text { Sem branqueamento } \\
\text { (peneira de } 0,8 \mathrm{~mm} \text { ) }\end{array}$ & $14,50 \pm 0,4 c$ & $3,60 \pm 0,1 \mathrm{a}$ & $1,06 \pm 0,0 \mathrm{a}$ & $18,16 \pm 0,0 \mathrm{ab}$ & $19,04 \pm 1,7 b$ \\
\hline
\end{tabular}

Médias \pm com expoentes diferentes em uma mesma coluna indicam diferença estatística $(\mathrm{p} \leq 0,05)$.

Tabela 6. Parâmetros de cor das polpas de mangaba sob diferentes processos de extração

\begin{tabular}{cccc}
\hline Despolpamento & $\mathbf{L}$ & $\mathbf{a}$ & $\mathbf{b}$ \\
\hline Com branqueamento (peneira de 0,5mm) & $56,04 \pm 0,08 \mathrm{c}$ & $4,32 \pm 0,07 \mathrm{a}$ & $33,14 \pm 0,07 \mathrm{a}$ \\
Sem branqueamento (peneira de 0,5mm) & $57,07 \pm 0,03 \mathrm{~b}$ & $4,15 \pm 0,03 \mathrm{~b}$ & $33,69 \pm 0,04 \mathrm{~b}$ \\
Sem branqueamento (peneira de 0,8mm) & $57,82 \pm 0,07 \mathrm{a}$ & $3,98 \pm 0,03 \mathrm{c}$ & $32,62 \pm 0,05 \mathrm{c}$ \\
\hline
\end{tabular}

Médias \pm desvio padrão. Médias com expoentes diferentes em uma mesma coluna indicam diferença estatística $(\mathrm{p} \leq 0,05)$

\section{Conclusões}

A textura e o teor de sólidos solúveis são excelentes indicativos de maturação dos frutos de mangaba do Cerrado. Os frutos de mangaba possuem alto rendimento em polpa (em torno de $77 \%$ ) e, portanto, possuem características interessantes para o processamento agroindustrial. As operações de despolpamento avaliadas foram eficientes com relação ao rendimento, pois resultaram em teores de polpa superiores à extração manual (72,5\% rendimento). O processo de extração da polpa diretamente dos frutos, sem trituração prévia ou branqueamento dos mesmos, utilizando uma peneira de $0,5 \mathrm{~mm}$ de abertura é o mais adequado para os frutos de mangaba.

\section{Agradecimentos}

À Universidade Estadual de Goiás - UnU Ipameri, à CAPES pela concessão da bolsa de doutorado e ao CNPq pela bolsa de iniciação científica.

\section{Referências Bibliográficas \\ ASSOCIATION OF OFFICIAL ANALYTICAL CHEMISTS - AOAC. Official methods of analysis of the Association of Official Analytical chemists. 14. ed. Washington, DC, EUA, 1984. \\ ASSOCIATION OF OFFICIAL ANALYTICAL CHEMISTS - AOAC. Official methods of analysis. $16 \mathrm{ed}$. Washington, DC, EUA, 1997.}


BENASSI, M. T.; ANTUNES, A. J. A comparison of metaphosphoric and oxalic acids as extractant solutions for the determination of vitamin $C$ in selected vegetables. Brazilian Archives of Biology and Technology, Curitiba-PR, v. 31, n. 4, p. 507-513, 1988.

BORGES, K. C. F.; SANTANA, D. G.; MELO, B.; SANTOS, C. M. Rendimento de polpa e morfometria de frutos e sementes de pitangueira-do-cerrado. Revista Brasileira de Fruticultura, Jaboticabal-SP, v. 32, n. 2, p. 471-478, 2010.

BRASIL. Ministério da Agricultura Pecuária e Abastecimento. Instrução normativa $\mathrm{n}^{\circ} 1$, de 7 de janeiro de 2000. Regulamento técnico geral para fixação dos Padrões de Identidade e Qualidade para polpa de fruta. Diário Oficial [da] República Federativa do Brasil, Brasília 10 de jan. 2000. Seção 1, p. 53.

CARNELOSSI, M. A. G.; TOLEDO, W. F. F.; SOUZA, D. C. L.; LIRA, M. de L.; SILVA, G. F.; JALALI, V. R. R.; VIEGAS, P. R. A. Conservação pós-colheita de mangaba (Hancornia speciosa Gomes). Ciência e Agrotecnologia, Lavras-MG, v. 28, n. 5, p. 1119-1125, 2004.

CHITARRA, M. I. F.; CHITARRA, A. B. Pós-colheita de frutas e hortaliças: fisiologia e manuseio. 2 ed. Lavras-MG: UFLA, 2005. 785p.

DIB TAXI, C. M. A.; MENEZES, H. C.; SANTOS, A. B.; GROSSO, C. R. F. F. Study of the microencapsulation of camu-camu (Myrciaria dubia) juice. Journal of Microencapsulation, London, v. 20, n. 4, p. 443-448, 2003.

GANGA, R. M. D.; FERREIRA, G. A.; CHAVES, L. J.; NAVES, R. V.; NASCIMENTO, J. L. Caracterização de frutos e árvores de Hancornia speciosa Gomes do cerrado. Revista Brasileira de Fruticultura, Jaboticabal-SP, v. 32, n. 2, p. 101-113, 2010.
HUNTERLAB. Applications note: CIE $\mathbf{L}^{*} \mathbf{a}^{*} \mathbf{b}^{*}$ color scale. Virginia, v. 8, n. 7, 1996.

MATTIETTO, R. A.; LOPES, A. S.; MENEZES, H. C. Estabilidade do néctar misto de cajá e umbu. Ciência e Tecnologia de Alimentos, Campinas-SP, v. 27, n. 3, p. 456463, 2007

PEREIRA, A. V.; PEREIRA, E. B. C.; SILVA JUNIOR, J. F.; SILVA, D. B. Mangaba. In: VIEIRA, R. F.; COSTA, T. S. A.; SILVA, D. B.; FERREIRA, F. R.; SANO, S. M. Frutas nativas da região Centro-Oeste do Brasil. Brasília-DF: Embrapa Recursos Genéticos e Biotecnologia, 2006, p. 188213.

SILVA, A. M. L.; MARTINS, B. A.; DEUS, T. N. Avaliação do teor de ácido ascórbico em frutos do cerrado durante o amadurecimento e congelamento. Estudos, Goiânia-GO, v. 36, n. 6, p. 1159-1169, 2009.

SILVA, M. R.; SANTOS JUNIOR, R. T. O.; FERREIRA, C. C. C. Estabilidade da vitamina $\mathrm{C}$ em cagaita in natura e durante a estocagem da polpa e refresco. Pesquisa Agropecuária Tropical, Goiânia-GO, v. 38, n. 1, p. 53-58, 2008.

SOUZA, F. G.; FIGUEIREDO, R. W.; ALVES, R. E.; MAIA, G. A.; ARAÚJO, I. A. Qualidade pós-colheita de frutos de diferentes clones de mangabeira Hancornia speciosa Gomes. Ciência e Agrotecnologia, Lavras-MG, v. 31, n. 6, p. 14491454, 2007. 